\title{
ASPECTOS ULTRAESTRUTURAIS DO ESPERMATOZÓIDE DE NATICA MAROCHIENSISH (GMELIN) (MOLLUSCA, GASTROPODA) DO LITORAL NORTE DO BRASIL
}

\author{
Edilson Matos ${ }^{1}$ \\ Patricia Matos ${ }^{2}$ \\ Graça Casal $^{3}$ \\ Carlos Azevedo ${ }^{4}$
}

\begin{abstract}
ULTRASTRUCTURAL ASPECTS OF TIIE SPERMATOZOON OF NATICA M.4ROCHIensish (GMelin) (Mollusca, Gastropoda) of tile Norti littoral of Brazil. Spermatozoa of Natica marochienssish (Gmelin, 1791) is described by light and electron microscopy. The spermatozoon is of the primitive type with head contains a conical acrosomal complex with an acrosomal vesicle of dense matrix having a basis occupied by the subacrosomal space. The middle piece shows the centriolar complex surrounded by mitochondria and the tail contains the axoneme with a 9+2.

KEY WORDS. Mollusca, Gastropoda, Natica marochiensish, ultrastructure, spermatozoa
\end{abstract}

Numerosas investigações sobre a estrutura de espermatozóides (BACCETTI \& AFZELIUS 1976; MAXWELL 1983) sugerem que o espermatozóide apresenta grande significado para a classificação taxonômica (HINSCH 1974). Baseado no fato de que o filo Mollusca é provavelmente o segundo maior filo animal (MAXWELL 1983), observa-se que existem poucos estudos morfológicos deste grupo, especialmente sobre a morfologia espermática e a fertilização (TOMPA 1984).

O presente trabalho apresenta aspectos morfológicos do espermatozóide, com especial referência aos componentes da cabeça, peça intermediária e cauda.

\section{MATERIAL E MÉTODOS}

Animais foram coletados nas praias de Ajuruteua ( $\left.00^{\circ} 50^{\prime} 55^{\prime \prime} \mathrm{S}, 46^{\circ} 36^{\prime} 30^{\prime \prime} \mathrm{W}\right)$ e transportados para Belém, Pará, onde em laboratório foram retiradas as gônadas e preparadas para microscopia óptica (MO) e microscopia eletrônica (ME). Os fragmentos de testículo foram retirados imediatamente, confirmados em microsco-

1) Departamento de Biologia Animal, Histologia e Embriologia, Faculdade de Ciências Agrárias do Pará. 66077-530 Belém, Pará, Brasil.

2) Departamento de Histologia e Embriologia, Centro de Ciências Biológicas, Universidade Federal do Pará. 66059-900 Belém, Pará, Brasil.

3) Laboratório de Biologia Celular, Instituto Superior de Ciências da Saúde. 4580 Paredes, Portugal.

4) Departamento de Biologia Celular, Universidade do Porto. 4050 Porto, Portugal. 


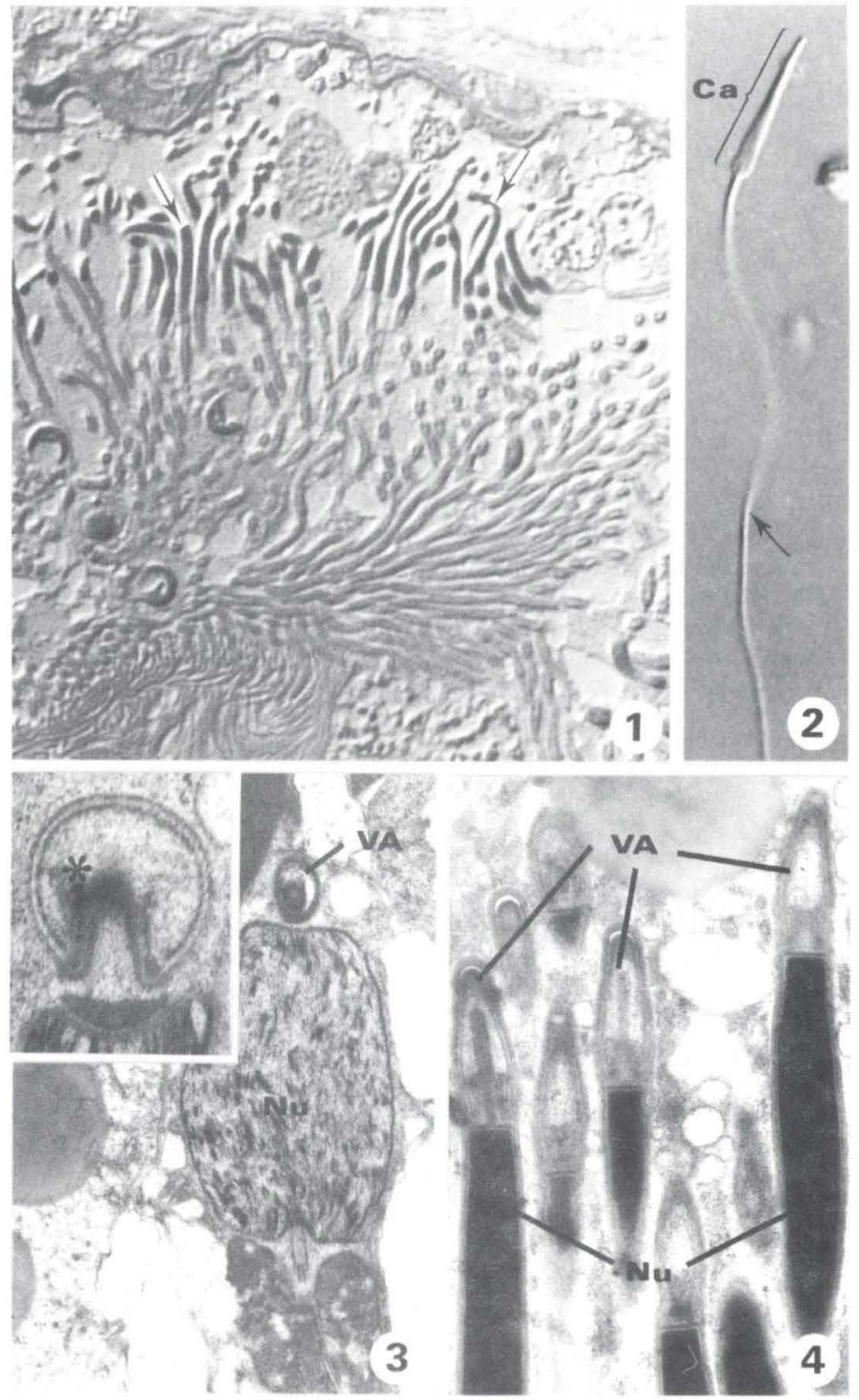

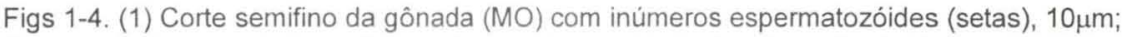
(2) espermatozóide maduro observado em microscopia óptica de contraste de interferência -

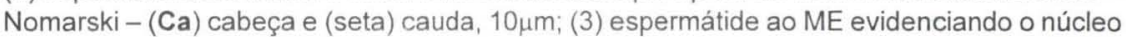
$(\mathrm{Nu})$ e vesícula acrosômica (VA) - inset: pormenor da vesicula acrosômica onde observa-se, em seu interior, deposição de material eletrodenso ( $\left.{ }^{*}\right), 2,5 \mu \mathrm{m}$, inset $=0,5 \mu \mathrm{m}$; (4) espermatozóides maduros (ME) podendo-se observar a cabeça constituída pelo núcleo e vesícula acrosômica, $1,5 \mu \mathrm{m}$. 
pia óptica, e fixados para microscopia eletrônica, em glutaraldeído a 3\% tamponado

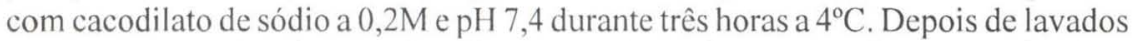
no mesmo tampão, durante duas horas a $4^{\circ} \mathrm{C}$, os fragmentos foram pós-fixados, durante duas horas a $4^{\circ} \mathrm{C}$, em tetróxido de ósmio a $2 \%$ devidamente tamponado. Sequencialmente os fragmentos foram desidratados em série crescente de álcool, seguida de três passagens em óxido de propileno. Depois de desidratado, o material foi incluído em Epon (MATOS et al. 1993). As observações foram feitas em cortes semifinos e em cortes ultrafinos, contrastados com acetato de uranila e citrato de chumbo, em microscópio eletrônico JEOL 100 CX II operando a 60Kv.

\section{RESULTADOS}

O espermatozóide de Natica marochiensish (Gmelin, 1791) é constituído por cabeça, com complexo acrosômico e núcleo, peça intermediária e cauda (Figs 1-2). Na fase de espermátide, a vesícula acrosômica apresenta uma forma esférica (Fig. 3) ocorrendo no seu interior a deposição de material eletrodenso (inset Fig. 3).

Posteriormente na fase de espermatozóide, a vesícula acrosômica modificase para uma forma cônica, sendo o seu interior constituído por zonas com diferentes eletrodensidades. O núcleo apresenta uma forma cilíndrica e encontra-se posicionado anteriormente em relação à peça intermediária (Fig. 4). Esta peça é ocupada por um complexo centriolar envolvido por mitocôndrias que apresentam uma forma aproximadamente esférica, em corte transversal (Fig. 5). Estas mitocôndrias em corte longitudinal, encontram-se envolvendo o axonema obliquamente e contém poucas cristas distribuídas irregularmente (Fig. 6). O centríolo proximal está localizado dentro da fossa nuclear e o distal apresenta-se constituído por 9p+2 microtúbulos. No flagelo entre o axonema e a membrana citoplasmática existe deposição de material granular com a função de substância de reserva (Figs 7-8).

\section{DISCUSSÃO}

Os espermatozóides de Natica marochiensish descritos neste estudo e outros espermatozóides descritos em outros trabalhos (AzEvEDo 1981; SMALDON \& DUFUS 1985) apresentam a forma de espermatozóide do tipo "primitivo". Existe pequena diferença entre as estruturas da peça intermediária e flagelo, mas o núcleo e o acrosoma são muito semelhantes na observação morfológica, havendo possibilidade de identificação de cada espécie por meio destas estruturas. Estudos comparativos da estrutura espermática de moluscos gastrópodes tem resultados similares a esta conclusão (THOMPSON 1973; HeAly 1983; Healy \& Willan 1984; SuMIKAWA \& FUNAKOSHI 1984). O fato de que estas espécies possuem um espermatozóide com uma única forma sugere que a morfologia pode ser válida para um caráter taxonômico (JAMIESON 1991; HEALY 1993).

A similaridade na estrutura espermática de cada grupo sugere também que em todos haja um ancestral comum. Muitos dos acrosomas tem áreas de eletrodensidade e eletrolucidez. Poucas diferenças têm sido mostradas nos acrosomas de bivalves (PoPHAM 1974; BERNARd \& HodgSON 1985) e em gastrópodes (LEWIS 

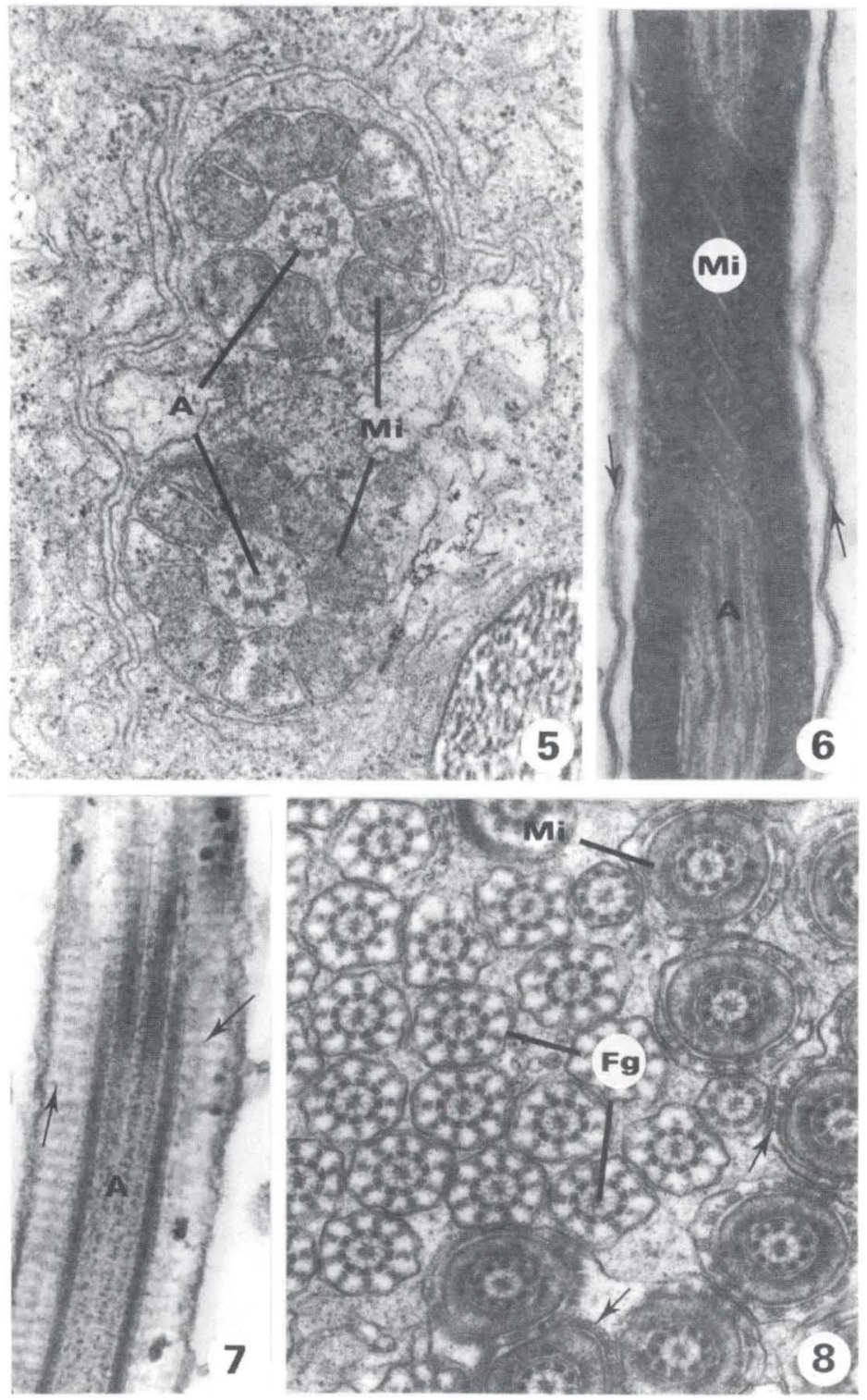

Figs 5-8. (5) Corte transversal da peça intermediária de dois espermatozóides ao ME evidenciando-se o axonema (A) rodeado por mitocôndrias (Mi), 0,5 $\mathrm{m}$; (6) corte longitudinal da peça intermediária (ME) mitocôndrias enroladas obliquamente ao longo do axonema e a membrana citoplasmática (setas), $0,5 \mu \mathrm{m} ;(7)$ corte longitudinal do flagelo de um espermato-

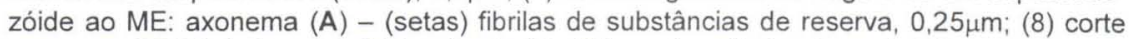
transversal (ME) de flagelos (Fg), mitocôndria (Mi) e microtúbulos (setas), 0,5 $\mu \mathrm{m}$. 
et al. 1980). Estas regiões de diferentes eletrodensidades podem provavelmente refletir funções diferentes dos acrosomas durante o processo de fertilização.

Alguns acrosomas apresentam uma estriação transversal, e o significado funcional disto propõe uma periodicidade do conteúdo acrosomal representando um alinhamento cristalino de enzimas (FRIEND \& FAWCETT 1974).

AGRAdECIMENTOS. À Profa. Dra. Yoko Wakabara (Universidade de São Paulo) pela identificação da espécie. Ao Sr. João Carvalheiro pelo serviço iconográfico. Trabalho parcialmente subsidiado pela Universidade do Porto/Portugal, FCAP, UFPa, CEPNOR/IBAMA, e Fundação Engenheiro António de Almeida (Portugal).

\section{REFERÊNCIAS BIBLIOGRÁFICA}

Azevedo, C. 1981. The fine structure of the spermatozoon of Patella lusitanica (Gastropoda: Prosobranchia), with special reference to acrosome formation. Jour. Submicrosc. Cytol. 13: 47-56.

Baccetti, B. \& B.A. Afzelius. 1976. The biology of the sperm cell. Basel, S. Karger, vol. 10.

BERnARD, R.T.F. \& A.N. Hodgson. 1985. Fine structure of the sperm and spermatid differentiation in the brown mussel Perna perna. S. Afr. Jour. Zool. 20: 5-9.

FRIEND, D.S. \& D.W. FAwCETT. 1974. Membrane differentiations in freeze-fractured mammalian sperm. Jour. Cell. Biol. 63: 6411-6664.

HEALY, J.M. 1983. Ultrastructure os spermatozoa of cerithiacean gastropods (Prosobranchia: Mesogastropoda). Jour. Morphol. 178: 57-75.

1993. Transfer of the gastropod family plesiotrochidae to the campaniloidea based on sperm ultrastructural evidence. Jour. Moll. Stud. 59: 135-146.

HEALY, J.M. \& R.C. WILLAN. 1984. Ultrastructure and phylogenetic significance of notaspidean spermatozoa (Mollusca, Gastropoda, Opisthobranchia). Zool. Scr. 13: 107-120.

HinsCH, G.W. 1974. Comparative ultrastructure of cnidarian sperm. Am. Zool. 14: 457-465.

JAMIESON, B.G.M. 1991. Fish evolution and Systematics: evidence from spermatozoa. Cambridge, Cambridge University Press, $319 \mathrm{p}$.

Lewis, C.A.; D.L. Leighton; V.D. VACQuiER. 1980. Morphology of abalone spermatozoa before and after the acrosome reaction. Jour. Ultrastruct. Res. 72: 39-46.

Matos, E.; P. Matos; E. Oliveira \& C. Azevedo. 1993. Ultraestrutura da espermatogenese do tamoatá Hoplosternum littorale (Hancock) (Teleostei, Callichthyidae) do rio Amazonas. Revta bras. Zool. 10: 215-218.

Maxwell, W.L.1983. Mollusca, p. 275-319. In: K.C. ADIYODI \& R.G. ADIYODI (Eds). Reproductive biology of invertebrates. Spermatogenesis and sperm function. Chichester, John Wiley and Sons, vol. 2.

PopHAM, J.D. 1974. The acrosome reaction in the sperm of the shipworm Bankia 
australis Calman (Bivalvia,Mollusca). Cell. Tissue. Res. 151: 93-101.

Smaldon, P.R. \& J.H. Dufus. 1985. An ultrastructural study of gametes and fertilization in Patella unegata L.. Jour. Moll. Stud. 51: 116-132.

SumiKAWA, S. \& C. FunAKOSHI. 1984. The fine structure of mature spermatozoa in two species of the Siphonaridae (Pulmonata: Basommatophora). Venus 42: 143-155.

THOMPSON, T.E. 1973. Euthyneuran and other molluscan spermatozoa. Malacologia 14: 167-206.

TOMPA, A.S. 1984. Land snails (Stylommatophora), p.47-140. In: A.S. TOMPA; N.H. VERdonK \& J.A.M. VAN DEN BiggelaAR (Eds). The Mollusca. Reproduction. New York, Academic Press, vol. 7.

Recebido em 04.VII.1996; aceito em 04.IX.1997 